\title{
MODA Y GLOBALIZACIÓN. De la estética de clase al estilo subcultural
}

\begin{abstract}
ANA MARTÍNEZ BARREIRO
Universidad de A Coruña

PALABRAS ClAVE ADICIONALES

Cambio Cultural, Individualismo, Modelos de difusión.

\author{
ADDITIONAL KEYWORDS \\ Cultural Change, Individualism, Models of \\ Diffusion.
}

RESUMEN. La hipótesis central de esta investigación consiste en cuestionar el modelo de "filtrado descendente" y argumentar la validez del modelo de la "virulencia" tras el impacto de la globalización económica y cultural. Este artículo consta de tres partes. Tras la presentación del marco conceptual de los tres modelos más aceptados de difusión de la moda, se examinan los cambios que trae consigo el paso de la producción en serie a la producción flexible en el sector textil y de la confección, que nos llevan a superar la visión del "filtrado descendente". Finalmente, se analizan las condiciones en que la globalización cultural nos enfrenta hacia un nuevo individualismo multicultural, esto es, a la estética como expresión del ambiente tribal. Esta última consideración nos invita a reconsiderar los modelos de referencia ante las condiciones de la globalización, y a afirmar que las nuevas modas no emanan de una sola fuente sino, que filtran desde distintos puntos y se propagan como el sida y las epidemias.
\end{abstract}

SUMMARY. The central hypothesis of this investigation consists in questioning the descending filtrate model and arguing in favour of the validity of the model of virulence following the impact of economic and cultural globalisation. This article comprises three parts. Following the presentation of the conceptual framework of the three most accepted models for the spread of fashion, an examination is carried out of the changes brought about by the move from production in series to flexible production in the textile industry and in garment manufacturing, which takes us beyond the vision of the descending filtrate. Finally, there is an analysis of the conditions under which cultural globalisation confronts us with a new multicultural individualism, that is to say, taste as an expression of the tribal environment. This last consideration invites us to reconsider the reference models under the conditions of globalisation and to affirm that new fashions do not emanate from a single source, but filter down from different points and propagate like AIDS and epidemics.

E-mail: anamb@udc.es

Revista Internacional de Sociología (RIS)

Tercera Época, No 39, Septiembre-Diciembre, 2004, pp. 139-166. 
RIS

REVISTA INTERNaCIONAL DE SOCIOLOGIA

No 39, SEPTIEMBRE-DICIEMBRE, 2004

ANA MARTINEZ BARREIRO

\section{INTRODUCCIÓN}

La globalización económica ha introducido cambios significativos en la producción, distribución de bienes y servicios y también en la comunicación en todas sus formas. Asimismo, los efectos de la globalización se sienten en el ámbito personal, incluso sobre las pequeñas opciones que tomamos en nuestra vida cotidiana -como lo que nos ponemos-, que forman parte del proceso de creación de nuestra propia identidad. Todas estas transformaciones nos están obligando a redefinir la validez de los modelos de difusión de la moda en las sociedades posmodernas. La hipótesis central de esta investigación consiste en cuestionar el modelo de filtrado descendente y argumentar la validez del modelo de la virulencia tras el impacto de la globalización económica y cultural. Este artículo consta de tres partes. Tras la presentación del marco conceptual de los tres modelos más aceptados de difusión de la moda, se examinan los cambios que trae consiguo el paso de la producción en serie a la producción flexible en el sector textil y de la confección, que nos llevan a superar la visión del "filtrado descendente". Finalmente, se analizan las condiciones en que la globalización cultural nos enfrenta hacia un nuevo individualismo multicultural, esto es, a la estética como expresión del ambiente tribal. Esta última consideración nos invita a reconsiderar los modelos de referencia ante las condiciones de la globalización, y a afirmar que las nuevas modas no emanan de una sola fuente, sino que se filtran desde distintos puntos y se propagan como el sida y las epidemias.

\section{LOS MODELOS DE DIFUSIÓN DE LA MODA. DEL GOTA A GOTA AL MODELO DE LA VIRULENCIA}

Hoy en día, las imágenes, artículos y estilos se difunden por el mundo con mucha mayor rapidez que nunca. El comercio, las nuevas tecnologías de la información, los medios de comunicación internacional y la emigración global son factores que han contribuido a que la cultura tenga tal libertad de movimientos que le permite cruzar fronteras con facilidad. La globalización ha cambiado fundamentalmente el carácter de nuestra experiencia cotidiana; por consiguiente, se hace necesario también abordar el tema de la difusión de la moda desde una perspectiva diferente; sobre todo se hace preciso examinar si el modelo de "filtrado descendente" mantiene su vigencia o, por el contrario, le sustituyen con ventaja otros modelos que aparecen tras el impacto de la globalización. Uno de los principales interrogantes en torno a la difusión cultural de la moda es el camino que ella sigue en su itinerario social. A este interrogante la sociología moderna ha dado dos respuestas: según la primera, las innovaciones en el campo de la moda y de los consumos en general se dirigen esencialmente a las clases superiores para difundirse después en sentido vertical desde las clases más altas a las bajas. Esto valdría para las 
sociedades pre-consumistas, investigadas por Veblen (1974), pero también para las consumistas, investigadas por Baudrillard (1974) y Bourdieu (1991), al tratarse de fenómenos dependientes de la estructura de clase en la sociedad capitalista. Este fenómeno, que es un proceso imitativo en términos de Simmel (1988), y un proceso emulativo vistoso en la terminología de Veblen, se conoce también con la denominación de trickle-down effect ${ }^{1}$. Se trata de un mecanismo que permite la difusión gota a gota de las modas, los nuevos estilos de vida y del consumo en general por el efecto que sobre los comportamientos tiene el sistema jerárquico de los estatus.

Otra de las respuestas pone de manifiesto que dentro de las sociedades de capitalismo maduro tras el efecto de la producción en serie, de la comunicación de masas y de la movilidad social, las innovaciones ya no tienen sólo como referencia a las élites sino a las clases medias; éstas son las auténticas innovadoras $\mathrm{y}$ protagonistas de la vida económica contemporánea. Partiendo de este cểntro propulsor, las modas culturales se difunden tanto hacia arriba como hacia abajo en la jerarquía social. La moderna sociedad de masas y de consumo resulta esencialmente móvil, dinámica e incluso igualitaria. Y la felicidad se concibe como algo visible a partir de una serie de objetos y signos. En este contexto de una mayor democratización de los procesos económicos y culturales surge la perspectiva pluralista de los modelos de difusión que nos aportan Ragone (1986), Konig (1972), Katz y Lazarsfeld (1970) y otros, considerando que los consumos innovadores nacen ahora en una zona intermedia o mercado medio, sustrayéndose del mecanismo de innovaciones que era típico del periodo anterior, en el cual las modas se formaban en las zonas de altos ingresos, para trasladarse después, por un fenómeno de atracción, al nivel de masas. De acuerdo con esta última postura, Wiswede (1971) propone el modelo de la virulencia. La palabra virulencia, en castellano, alude al poder que tienen las bacterias para reproducirse y segregar sustancias tóxicas y que transmiten a otros seres. Por consiguiente, se trata de un esquema de difusión de la moda por contagio, y de una forma de propagación como la del sida o las epidemias.

En los últimos años se ha observado un gran interés científico por los procesos de contagio en la moda o en la difusión cultural. El hito indiscutible es el nuevo campo de estudio llamado memética. El biólogo Richard Dawkins (2000) presenta su teoría de la evolución cultural basada en la competencia entre genes e introduce el concepto de meme. Un meme es la unidad mínima de transmisión cultural. El meme pertenece a la dimensión del contagio, la propagación y la infección. La esencia del meme es la replicación. Cualquier idea, moda o concepción que pasa de una persona a otra por imitación, es un meme. Una idea científica, una canción o

\footnotetext{
${ }^{1}$ El término Tröpfelmodell (modelo gota a gota) es empleado por el sociólogo G.Wiswede (1971: 87).
} 
RIS

REVISTA INTERNACIONAL DE SOCIOLOGÍA

No 39, SEPTIEMBRE-DICIEMBRE, 2004

ANA MARTINEZZ BARREIRO

una moda como la minifalda en los años setenta o el piercing en los años noventa, pueden ser considerados memes, como los virus informáticos. Susan Blackmore (2000) aplica el modelo mimético a diferentes cuestiones. Según la autora, si un meme puede reproducirse y difundirse lo hará. Desde la perspectiva semiótica, esta autora introduce la distinción entre los memes basados en la reproducción de un producto (copy the product) y los memes basados en la difusión de instrucciones (copy the instruction). La memética se presenta como una perspectiva aplicable a cualquier fenómeno cultural y por consiguiente a los fenomenos de difusión y las modas.

Lipovetsky (1990) se cuestiona también el modelo de la transmisión vertical. A su juicio, con el surgimiento de la sociedad abierta, se inicia un nuevo régimen de difusión en la moda. La ley de imitación vertical es sustituida por la imitación horizontal. El modelo piramidal, donde los artículos nuevos se difunden a partir de las clases superiores e invaden paulatinamente a las clases inferiores, ya no es válido o pertinente en sentido global. Durante mucho tiempo la lógica social de la moda fue la de distinguirse socialmente mediante la manera de vestir. Sin embargo, con el surgimiento del prêt-a-porter y el fin de las tendencias de temporada marcadamente unificadas se vaticina el final del dirigismo disciplinario de la apariencia, y la aparición de la multiplicidad estética. Ya no hay una sola moda, sino una multiplicidad de modas igualmente legítimas (Lipovetsky, 1990: 119-171; 1993). Frente a esa fragmentación estilística, se producen otros cambios muy significativos. En primer lugar, se constata una mayor autonomía de los consumidores en relación con las novedades. Mientras en la fase anterior había que adoptar los últimos modelos lo más rápidamente posible, en la actualidad, por el contrario, la tendencia es meramente indicativa. Ya no hay una correspondencia entre la innovación y la difusión, entre la vanguardia creativa y el público consumidor, pues la calle se ha emancipado de la fascinación de los líderes de la moda y asimila las novedades a su ritmo y a su antojo. Así, es muy difícil estar absolutamente demodé. En segundo lugar, cuando ya no hay moda unitaria el look funciona a la carta (1990:161). Las mujeres continúan siguiendo la moda, pero de manera más libre. Llevan lo que les gusta, lo que les va, no la moda por la moda. El mimetismo directivo característico de la moda clásica ha dado paso a un mimetismo de tipo optativo. Se imita lo que se quiere, cuando se quiere y como se quiere. En tercer lugar, la moda entra en la era desapasionada del consumo, en la era de la curiosidad relajada y diversificada. La lógica cool ha invadido el espacio de la moda. En cuarto lugar, otro de los efectos más importantes del individualismo contemporáneo respecto a la moda es que ha reducido el símbolo jerárquico en favor del placer, la comodidad y la libertad. Pues a través del vestido ya no se busca prioritariamente hacer alarde de pertenencia a una clase social, sino de un gusto, de un estilo de vida pasando del status símbolo al estilosimbolo. Los análisis de la sociología moderna, representada hoy por Bourdieu y Baudrillard, parecen haber olvidado una parte esencial de la explicación de la 
moda contemporánea al haber permanecido ciegos a un nuevo tipo de regulación social cuya base es la seducción individual y estética (Lipovesky, 1990: 170). De ahí la vigencia del modelo de la virulencia: mimetismo horizontalmente inducido por contagio mediante su difusión capilar a través de las superficies de contacto entre los grupos de pares o iguales, que comparten el mismo estrato social.

En las sociedad de masas el control sobre la difusión del gusto y de las modas se realiza de forma indirecta, dado que el poder ha perdido sus cualidades tradicionales, la de ser espectacular y reconocible, haciéndose más abstracto y anónimo sin alterar por ello su posición estructural. Esto se debe a dos motivos: en primer lugar, ante el desarrollo de los grandes aglomerados urbanos es imposible ejercer cualquier tipo de influencia directa y primaria en las relaciones cara a cara. La apariencia se convierte en el único medio de descifrar al "otro" en un entorno desconocido (Wilson, 1985: 137). En segundo lugar, en esta etapa de desarrollo económico, la conservación de los privilegios por parte de la clase acomodada ya no es independiente de la mejoría de las condiciones de vida de las clases subordinadas. Por consiguiente, hay que reconocer la existencia de nuevos intermediarios culturales, produciéndose una recomposición de los cuadros de referencia.

La teoría del filtrado descendente ha sido criticada también por Rouse (1989), según el cual, si la teoría de la filtración descendente depende del intervalo de tiempo entre el momento en que las élites adoptan la moda y aquel en que llegan a los nuevos modelos a ser adoptados por las clases más bajas, esta postura ya no es aplicable en las sociedades posmodernas, porque, dado el volumen de producción actual y la creciente globalización de la producción y el masificado consumo ese intervalo de tiempo prácticamente ha desaparecido. Por su parte, Braham (1997) considera que la alta costura, como innovadora principal, ha perdido importancia en la moda contemporánea. Las grandes firmas de moda, propiedad de grupos multimillonarios, han conseguido borrar la línea divisoria entre la alta costura y la moda de la calle, tal como puede observarse en el amplio número de franquicias de estas firmas de moda que operan a escala mundial. De igual modo, el cambio vestimentario no tiene lugar porque las clases inferiores lleven las ropas de los ricos (propio de la sociedad pre-consumista de Veblen), sino porque en numerosas ocasiones la clase trabajadora y otros grupos sociales influyen en sentido inverso y se convierten en modelos de referencia.

A partir de lo expuesto, el sociólogo Squicciarino (1990:166) añade otro modelo que él define como el de las marionetas o Trickle-effect perfeccionado. Este último modelo pone de manifiesto que en las sociedad de consumo maduro, aunque se dé una mejora general del nivel de vida, subsiste, a pesar de las apariencias, una relación piramidal disfrazada entre las clases sociales, en las que de forma oculta y a través de los medios de comunicación de masas, se sugiere constantemente a las clases inferiores modelos de comportamiento con un esquema del tipo consumo-dependencia. Cuanto más se dé el bombardeo publicitario del consumo, 
más alta será la probabilidad de que las masas sean manipuladas y engañadas por los hilos invisibles del poder económico.

En la misma línea, Baudrillard (1974) afirma que ningún objeto de consumo emerge espontáneamente del consumidor básico si antes no aparece en el select package $^{2}$ de las necesidades. El consumo de objetos se filtra hacia abajo en virtud de un principio absoluto: la conservación de las distancias a través del sistema de signos (1974:75). De ahí que las necesidades de las clases medias estén siempre sujetas a aparecer con una cierta distancia en el tiempo en relación con las de las clases superiores. $\mathrm{Al}$ parecer, ésta era una de las formas más frecuentes de segregación en la sociedad de consumo de masas. Por su parte, Bourdieu (1991) considera que el error inherente al modelo del trickle-down effect reside en el hecho de reducir a una búsqueda intencional de la distinción, lo que en realidad es un efecto objetivo y automático de las condiciones de los consumidores y de la diferenciación de la producción en las sociedades contemporáneas (1991:224).

La exposición anterior nos sugiere que para comprender la moda es necesario trascender el argumento del itinerario social, puesto que lo que se define y reconoce como moda es el producto de una cadena de actividades industriales, económicas y culturales. Lo que distingue el código de la moda es que ha de pasar por el filtro de la industria de la moda, de manera que las modificaciones del código presentadas en las pasarelas se exponen a ser rechazadas por una serie de publicistas y periodistas de la moda, pero también por los fabricantes y los compradores. En la actualidad, numerosos autores como Fine y Leopold (1993), al igual que Braham (1977), arguyen que la moda no es sólo cultura, sino también industria, no trata sólo del consumo, sino también de la producción. Por consiguiente, para comprender el funcionamiento del sistema de la moda hemos de apartarnos del modelo de filtrado descendente, que ha supuesto la base de muchas discusiones sobre la moda y su difusión, y contemplar la moda como resultado de procesos socioeconómicos más complejos tras el desarrollo de la sociedad de consumo y el impacto de la globalización económica y cultural.

\section{EL IMPACTO DE LA GLOBALIZACIÓN ECONÓMICA: DE LA PRODUCCIÓN EN SERIE A LA PRODUCCIÓN FLEXIBLE}

En las últimas décadas, ha surgido una nueva economía a escala mundial, esto es, la economía informacional y global. Es informacional porque la productividad y competitividad de las unidades o agentes de esta economía (ya sean empresas,

\footnotetext{
${ }^{2}$ Standard-package, según Riesman: “conjunto de bienes y servicios que constituyen la especie de patrimonio clásico del americano medio". Select-package, idéntico significado salvo que referido a las élites sociales.
} 
regiones o naciones) dependen de su capacidad para generar, procesar y aplicar con eficiencia la información. Y es global porque la producción, el consumo y la circulación, así como sus componentes (capital, mano de obra, materias primas, gestión, información, tecnología, mercados) están organizados a escala global. En lo que sigue, trataré de presentar algunos indicadores que permitan conocer y comparar el sector textil y de la confección, explicar el conjunto de dispositivos organizativos que existen en el sector y, finalmente, observar la relación entre economía y cultura. Pues lo que tienen en común los líderes mundiales de la industria textil de la confección no es sólo una breve historia y una salida reciente al mercado internacional, sino que les unen una cultura empresarial y un apoyo en una mercadotecnia sofisticada, que aprovecha internamente las mayores ventajas que les proporciona una economía cada vez más internacionalizada.

Se ha dicho que las empresas de la confección textil presentan una existencia efímera, siendo continuamente reemplazadas unas por otras (Singleton, 2000). Es verdad que la dificultad de mantener la ventaja competitiva - por ejemplo, el bajo coste del empleo - ha hecho modificar la estructura internacional del sector, de modo que sociedades que hace sólo unos lustros eran pioneras en la exportación, ahora no resultan más que meras caricaturas de lo que en algún momento fueron, $y$ eso en el caso de que aún no hayan desaparecido del mercado. Pero también es cierto que firmas que hace sólo treinta años no eran más que modestos negocios, donde fabricantes y distribuidores eran los propios componentes de la unidad familiar, constituyen en la actualidad lo que en el argot empresarial se califica como killers y siguen gozando de excelente salud. El mapa actual de la confección textil global no tiene nada que ver ya con el de hace 20 años, ni en el tamaño de las empresas, ni en los nombres de las sociedades que lideran el sector, ni en el volumen generado por sus exportaciones, ni en los países donde asientan sus sedes. El más significativo de las actuales killers de la confección, la norteamericana Gap, fue creado por dos desconocidos, Don y Doris Fisher, en San Francisco en 1969. Lo mismo sucede con Ann Taylor, la diseñadora de moda femenina, cuyos orígenes datan de 1954, cuando abrió su tienda en New Haven. The Limited fue creada en 1963 en la localidad de Columbus (Ohio). La suiza Charles Vögele es sólo un poco anterior, de 1955, y la británica Next data de una fecha muy reciente (1982), aunque no tanto como la española Mango (1987). Por supuesto que no todos los killers disfrutan de semejante juventud. En algunos casos proceden de algo más atrás (la norteamericana Abercrombie \& Fitsh, la italiana Benetton, la holandesa $C \& A$, la sueca Hennes \& Mauritz), pero en realidad han comenzando a operar como líderes a partir de los años 70 y 80 (y algunas, como $C \& A$ o Marks \& Spencer, no han podido soportar la durísima competencia y han visto reducidos sustancialmente sus mercados en los últimos tiempos). Otro caso es el grupo de Diseño Textil, S.A. (Inditex), más conocido por Zara, que de vender confección doméstica en el mercado local durante la década de los sesenta, ha pasado a diseñar, producir y distribuir todo tipo de prendas de 
vestir y complementos para el consumo de masas en 33 países - en tres continentes-, compitiendo ventajosamente con líderes, como la estadounidense Gap o l̀a sueca Hennes \& Mauritz, y superando a otras que hasta no hace mucho se situaban entre las más relevantes.

Entre algunas de las razones que explican la creciente presencia de la confección española en los mercados exteriores podemos señalar la progresiva apertura de nuestra economía, la búsqueda de respuestas internacionales a los movimientos competitivos de las empresas extranjeras en los mercados domésticos, la homogeneización en las preferencias del consumo de masas y la rápida difusión de las tecnologías, en especial las de transferencia de la información ${ }^{3}$. En el tabla 1 pueden verse las diez mayores firmas españolas del sector de la confección, en el que se encuentra en primer lugar el holding Inditex, tanto por volumen de ventas como por beneficios netos y demás parámetros.

A continuación trataremos de dar cuenta del conjunto de dispositivos organizativos que existen en la economía informacional y que afectan al sector de la industria textil y de la confección. Todos estos avances, incluyendo la creciente globalización de la producción y el consumo, han sido bautizados bajo la rúbrica de pos-fordismo o producción flexible. La reestructuración económica de la década de 1980 introdujo diversas estrategias de reorganización en las firmas comerciales. Algunos analistas, en particular Piore y Sabel (1990), sostienen que la crisis económica de los años setenta fue el resultado del agotamiento del sistema de producción en serie y constituyó una segunda "revolución industrial" en la historia del capitalismo. En las tres últimas décadas se han introducido prácticas flexibles en diversas esferas, entre ellas, en el desarrollo de productos, en las técnicas de producción, en los modelos de gestión, en el entorno laboral, en la participación del empleado y en la comercialización. Para otros, como Harrison (1994) la difusión de las nuevas formas organizativas ya se había practicado en algunos países o empresas durante muchos años y fue la respuesta a la crisis de rentabilidad que sufría el proceso de acumulación de capital. Algunos, como Coriat (1994), sugieren una evolución a largo plazo del "fordismo" al "postfordismo", como expresión de una gran "transición": la transformación histórica de la relación entre producción y productividad, por una aparte y, por otra, entre consumo y competencia. Pero, a pesar de la diversidad de planteamientos, existe coincidencia en varios puntos fundamentales del análisis.

La primera y más amplia tendencia de la evolución organizativa que se ha identificado es la transición de la producción en serie a la producción flexible. Cuando la demanda se volvió impredecible en cantidad y calidad, cuando los mercados se diversificaron en todo el mundo y, en consecuencia, se dificultó su control,

\footnotetext{
${ }^{3}$ Tomo este análisis de Flavián Blanco y Polo Redondo (2000: 141).
} 
Tabla 1.

Los líderes de la confección textil en España en 1999

\begin{tabular}{lcccc}
\hline Grupos y Empresas & Facturación & Beneficios netos & Cash Flow & Recursos propios \\
\hline Inditex & 338.607 & 34.314 & 53.031 & 148.613 \\
Cortefiel & 99.683 & 8.145 & - & - \\
Mango (Punto Fa) & 70.148 & 9.769 & 11.897 & 28.164 \\
Sara Lee España & 64.930 & - & - & - \\
Induyco (El Corte Inglés) & 57.583 & 584 & 1.081 & 4.327 \\
Burberry Spain $\left(^{*}\right)$ & 32.778 & 3.200 & 3.900 & 14.000 \\
Benetton España & 22.700 & 2.123 & 3.369 & 4.520 \\
Levi Strauss España $\left(^{* *}\right)$ & 20.850 & 1.163 & 2.638 & 1.493 \\
Grupo Sáez Merino & 20.705 & 3.412 & 2.731 & 8.007 \\
Vives Vidal Vivesa $\left(^{*}\right)$ & 15.945 & 658 & - & 6.131 \\
Corp. Empresarial Valls & 14.989 & 838 & 1.793 & 8.843 \\
\hline
\end{tabular}

Fuente: Web del Centro de Información Textil y de la Confección (Cityc) Born. Las unidades monetarias, en millones de pesetas. (*) Datos de 1998; (**), datos de 1997.

cuando el ritmo del cambio tecnológico hizo obsoleto el equipo de producción de cometido único, el sistema de producción en serie se volvió demasiado rígido y costoso para las características de la nueva economía. Una respuesta para superar esa rigidez fue la producción flexible o especialización flexible, que, gracias al diseño por ordenador, junto con otros tipos de tecnologías informáticas, han cambiado radicalmente la situación anterior: ahora se trata de producir cantidades de productos menores y más individualizados que con los procesos de producción masivos. Cuando los consumidores exigen determinados tipos de bienes, la producción flexible permite a las empresas diversificar su línea productiva con el fin de responder a las nuevas necesidades. Las nuevas tecnologías de la información permiten la transformación de las cadenas de montaje características de las grandes empresas en unidades de producción fáciles de programar que pueden ser sensibles a las variaciones del mercado (flexibilidad del producto) y a los cambios de los insumos tecnológicos (flexibilidad del proceso).

Pero lo que hace posible esta producción flexible deriva en parte de la elevada integración vertical. En el sector existen varias modalidades de integración: la predominante, que incluye únicamente los procesos de diseño y comercialización (Gap, Hennes \& Mauritz, Abercrombie \& Fitch, Ann Taylor, The Limited, Next, Charles Vögele), pero deja fuera la fabricación, que se subcontrata a otras sociedades (en muchos casos de actividad sumergida o de países asiáticos donde 
RIS

REVISTA INTERNACIONAL DE SOCIOLOGIA

№ 39, SEPTIEMBRE-DICIEMBRE, 2004

ANA MARTÍNEZ BARREIRO

no existe reglamentación laboral), y el modelo Benetton (Benetton, Mango), que integra los procesos de diseño y fabricación, pero la comercialización se realiza al por mayor a través de franquicias y sólo raramente por medio de joint ventures o tiendas propias 4 . El modelo Inditex constituye la suma de los dos anteriores, aunque en grado diferente. Inditex actúa mediante un modelo integrado desde el diseño, el aprovisionamiento de materias primas (el $40 \%$ interno), la producción (en un $40-50 \%$ de producción propia), la red logista y las tiendas ( $92 \%$ propias) (Castellanos, 2004: 9-11).

$\mathrm{Al}$ revisar la historia del grupo Inditex más conocido como Zara percibimos, como primera ventaja, la producción flexible en términos de rápida respuesta de la oferta a una demanda muy cambiante, algo que en el resto de killers es menor o simplemente no existe. En Inditex se realiza una perfecta sincronización en los procesos de producción y distribución, que eliminan los cuellos de botella o estrangulamientos, con lo que puede anticiparse en mejores condiciones a su competencia. Esta sincronización se inicia en el diseño (creación de telas y de modelos, para lo que dispone en sus centros de 200 diseñadores); pasa por el aprovisionamiento de tejidos en crudo - adquiridos, a través de sociedades del grupo (Comditel, Inditex Asia), en gran parte en China, pero también en India, Marruecos, Turquía, Alemania e Italia, una variedad que permite reducir el poder de negociación de los aprovisionadores-, y le siguen el tintado, el patronaje, la confección, el acabado final y la distribución y comercialización.

Pero lo que hace posible esta producción flexible deriva en parte de la elevada integración vertical del grupo gallego. Inditex es la única empresa de confección textil en el ámbito internacional que dispone también de proceso de fabricación propio. La integración es muy alta en las operaciones de aprovisionamiento de materias primas, las fases del proceso productivo más intensivas en capital - diseño, patronaje, corte, tinte, parte de la fabricación, control de calidad, planchado, embalaje y etiquetado - y la distribución (véase el tabla 2, que reproduce las actividades de cada una de las sociedades de Inditex). Pero es baja o no existe en aquellas fases del proceso más intensivas en empleo, como el ensamblado final de sus componentes (en la actualidad, menos de la mitad de la producción). Estas fases son subcontratadas a talleres, cooperativas y sociedades laborales independientes pero próximas (Iglesias Pérez, 2000) - básicamente en la provincia de A Coruña y, en menor medida, en el resto de Galicia y norte de Portugal, en especial, en áreas rurales (Cabanelas Omil, 1997), lo que supone una actividad de auxilio para las economías familiares-a las que proporciona tecnología, logística y apoyo

\footnotetext{
${ }^{4}$ En la confección textil no existe aún el modelo Nike, que mantiene tan sólo el diseño sin integrar la fabricación y la distribución. Véanse Jesús $M^{a}$ Valdaliso y Santiago López (2000: 279), quienes toman las referencias de M.T. Donaghu y R. Barff (1990), «Nike just did it: International Subcontracting and Flexibility in Athletic Footwear Production», Regional Studies, 24, 6:537-552.
} 
Tabla 2.

Actividad de las sociedades del grupo Inditex. 2000.

\begin{tabular}{lc}
\hline Sociedades del grupo & Número \\
\hline Comercialización & 42 \\
Fabricación & 21 \\
Inmobiliarias, promoción y construcción & 11 \\
Logística & 4 \\
Central de compras & 3 \\
Cartera & 3 \\
Financiera & 2 \\
Compra y tratamiento de tejido & 1 \\
Explotación de marcas & 1 \\
Decoración & 1 \\
Comercialización calzado & 1 \\
Planta de cogeneración & 1 \\
Sin actividad & 8 \\
Total & 99 \\
\hline
\end{tabular}

Fuente: Informe anual 2000.

financiero, pero a las que se exige un elevado control de calidad y una rigurosa adecuación a la legislación vigente en materia laboral y fiscal ${ }^{5}$. Todas ellas están especializadas en un sólo producto, que venden en exclusiva a Inditex, que impone precios y, consecuentemente, capitaliza el valor añadido. El sistema comenzó a ser utilizado en 1983-84 a partir de una de las empresas participadas por el grupo (Confecciones Fíos) y se incrementó desde finales de los 80 a raíz de su primera expansión internacional (Portugal, Estados Unidos y Francia). Con todo, Inditex es el killer del sector que en menor medida depende de la subcontratación ${ }^{6}$.

\footnotetext{
${ }^{5}$ Junto a los procesos de fabricación, existen subcontratas también en el transporte y almacenes.

${ }^{6}$ Sobre estas cuestiones, puede consultarse la página web de la organización no gubernamental Setem [http://www.pangea.org/ropalimpia] que, a través de la campaña «Ropa limpia», ha logrado sensibilizar a la opinión pública europea. En este sentido, uno de los últimos informes sobre el textil de la Organización Internacional del Trabajo (OIT, 2000) señalaba que la globalización económica había estimulado a las multinacionales a deslocalizar la fase de confección, trasladándola a países y áreas deprimidas, en donde los costes de empleo se manifestaban muy inferiores. En este contexto de armonización de los códigos de conducta ha de entenderse la iniciativa del Parlamento Europeo (Actas de la reunión del 15 de enero de 1999) y, sobre todo, la más reciente de Naciones Unidas, que pretende promover un compromiso entre las multinacionales con subcontratas para que asuman la adopción de nuevos principios generales para proteger los derechos de los trabajadores y del medio ambiente.
} 
RIS

REVISTA INTERNACIONAL DE SOCIOLOGLA

№ 39, SEPTIEMBRE-DICIEMBRE, 2004

Frente a la práctica de muchos de sus competidores, que compran la mayor parte del producto acabado en lejanos mercados asiáticos, en la estrategia de Inditex es fundamental la proximidad entre las cooperativas y la casa matriz, lo que permite acortar tiempos entre fabricación y distribución y dotar al negocio de mayor flexibilidad (Cabanelas Omil, 1997). Para Valdaliso y López (2000), la cercanía de los proveedores a las plantas de los fabricantes permiten desarrollar al máximo el procedimiento just in time (2000:493). Además, muchos de los subcontratistas de Inditex están relacionados por lazos de parentesco con los empleados de sus fábricas y oficinas, una situación similar a la que se produce en las factorías de Benetton (Bonache y Cerviño, 1996: 66).

La utilización generalizada del sistema de subcontratación, tanto en los países en desarrollo como en los desarrollados, constituye uno de los factores que proporcionan flexibilidad a las empresas textiles, en cuanto permite ampliar o reducir la escala de la producción en función de las oportunidades del mercado, pero comporta efectos sociales que se ve por algunos como indeseables. No obstante, el conocimiento por parte de la opinión pública de algunas de estas prácticas ha generado un problema de imagen corporativa que se ha vuelto contra las propias empresas, hasta el punto de que los bajos costes del trabajo pueden no compensar la caída de la facturación derivada, por ejemplo, de un boicot a una marca. Recuérdense al respecto las campañas contra Nike, provocadas por la utilización del trabajo infantil en Indonesia, y contra $C \& A$ en Zimbabwe, donde fueron despedidos 13.000 trabajadores que protestaban por su precariedad laboral, para ser readmitidos de nuevo en condiciones aún más rigurosas (Castellano, 1993: 403).

Otra de las ventajas de la producción flexible es el modelo just in time, basado en pequeñas cadenas independientes y que permite modificar sobre la marcha la producción y adaptarla a los cambios observados en la demanda. De hecho, en el sector de la confección que es el que sostiene el paradigma de la moda, y en el que las preferencias de los consumidores son tan variables, resulta fundamental efectuar estos cambios en la clásica cadena, porque son los que dan flexibilidad al conjunto. Por consiguiente, la flexibilidad ha sido acrecentada gracias al sistema de JIT pues, además, permite ordenar los datos sobre las ventas entre fabricantes y minoristas y permite operar con niveles de inventario mínimos. La creciente importancia de seguir el ritmo de la moda condujo a hacer hincapié en partidas más pequeñas para reducir el riesgo de superávit. La producción se lleva a cabo, en la medida de lo posible, basándose sólo en pedidos firmes de minoristas. Esta flexibilidad ha sido acrecentada en los últimos años, a través de un depurado sistema informático que comunica en tiempo real la caja realizada, los artículos que se venden, las tallas más solicitadas en los establecimientos, etc. La rapidez de acceso de las prendas al mercado incrementa doblemente la flexibilidad en un sector de bienes tan efímeros.

Nueno (El País, 2001:152-158) distingue cuatro modelos de fabricación en la industria de la confección. El tradicional necesita de un ciclo de más de 300 días. Es un modelo muy arriesgado y responde a un momento pasado en el que las 
marcas tenían autoridad sobre los consumidores. Ahora es al revés. Un segundo modelo sería un híbrido. Como el de Adolfo Domínguez, una parte sigue la pauta del primer modelo, junto a unas producciones más cortas y más flexibles, que garantizan una rotación en las tiendas. Un tercer modelo sería el de Mango, de mucho éxito en los últimos 10 años. Tiene una colección con coherencia. Es lo que ahora se resume con el aforismo de orientación-moda. Esas colecciones se producen en países asiáticos o del norte de África y se ponen en tienda. Se les da una rotación y lo que no se vende se pone en rebajas. Todo ello está dando un notable éxito. Como ocurre también con el modelo Zara. Parte de una colección fija, que viene a ser el $60 \%$ de su producción, con prendas que Inditex denomina básicas, y que no pasan de moda. Luego, el $40-50 \%$ restante son prendas oportunistas susceptibles de estar en las tiendas cada dos semanas. Dice Nueno que los just in time son buena parte de los 15.000 modelos diferentes (sin contar tallas o colores) que Inditex es capaz de poner en el mercado en un año. Y le dan vueltas al surtido, entre otras cosas, porque sus centros de producción están muy cerca, ya sea en Galicia, donde operan cerca de 150 cooperativas ahora convertidas en sociedades, como en el norte de Portugal, independientemente de las producciones que se encargan a países asiáticos o del norte de África.

En Inditex la flexibilidad ha sido acrecentada exponencialmente en los últimos años con la creación de un centro logístico que se mantiene comunicado permanentemente y en tiempo real con los 1.080 puntos de venta de que disponía el holding a fines de 2000. De este modo, cada encargado comunica diariamente (y dos veces por semana de una manera muy detallada) a través de un depurado sistema informático la caja realizada, pero también los artículos, los colores y las tallas más solicitadas en su establecimiento. Así se pueden reponer muy rápidamente - Inditex lo hace dos veces por semana, recurriendo para ello a una flota de camiones y al transporte aéreo-, con lo cual se acrecienta doblemente la ventaja, pues a la adquirida por la rápida reposición de la mercancía más demandada, se añade la disminución radical de los costes financieros vinculados al almacenaje y mantenimiento (tanto de materias primas, como de productos en curso y acabados) y, lo que es más importante en un sector de bienes tan efímeros, el coste de obsolescencia (Castellano, 1993: 403).

Un último elemento que contribuye a desarrollar la flexibilidad productiva es la descentralización y autonomía que poseen de cada una de las marcas comerciales en la gestión de sus negocios respectivos. Sus equipos de dirección son independientes en la toma de decisiones comerciales y en la forma en que administran sus recursos. En Narón-Ferrol se localiza el de Pull \& Bear; en la provincia de Barcelona (Tordera y Sabadell), los de Massimo Dutti, Bershka y Stradivarius, y en Arteixo (A Coruña), el de Zara y los servicios centrales corporativos que comparten todas las cadenas y facilitan el crecimiento internacional, la administración, el uso de tecnología logística, la política general de recursos humanos, los aspectos jurídicos, financieros y otros. 
La mayor evidencia de su flexibilidad productiva reside en la rapidez de acceso al mercado de las prendas de Inditex. Mientras que su competencia necesita de una media de 6 meses para diseñar el producto y otros 3 meses para fabricarlo y colocarlo en los puntos de venta, la firma gallega lo hace, para el primer caso, entre 3 y 4 semanas y, para el segundo, en 7 días, es decir, reduce el tiempo de acceso al mercado en más de un $80 \%$. De este modo, la flexibilidad constituye la mayor ventaja competitiva de Inditex, colocándose a una distancia considerable del resto de sociedades del sector (MSDW, 2000).

Otra de las características del sistema de la producción textil es la diversificación de la oferta en función de las características del mercado. Se trata de una estrategia que aplican muchas firmas y que ha favorecido en las últimas décadas la expansión. Aquellas sociedades que no producen para un mercado segmentado acaban acusándolo en la cuenta de resultados ( $C \& A$, Marks \&Spencer). El marketing de nicho, que surgió en los años ochenta, consiste en producir para un mercado de consumidores muy segmentado según distintas variables como la identidad, la edad, el capital económico y el gusto, entre otras. Los nichos de mercado describen "agrupaciones afectivas que emergen a través de unos sistemas compartidos de códigos simbólicos como el adorno, el gusto y el habitus" (Shields, 1992: 14). En España el grupo Inditex ha sido una de las primeras firmas del sector en incorporarla, aunque la innovadora en este caso fue la firma americana Gap. Inditex ha creado cinco marcas de comercialización bien diferenciadas: Zara, la más antigua, de 1975, con carácter generalista, pretende vestir a la familia joven de clase media (padre, madre e hijos pequeños); Massimo Dutti, destinada a satisfacer tramos de mayor standing de la moda de masas tanto masculinos como femeninos. Pull\& Bear, destinada a un público joven de ambos sexos que desean gastar poco e imprimir gran rotación a su vestuario. Las últimas son Bershka y Stradivarius, creadas en 1992. En el primer caso, de trata de hacer prendas deportivas, para chicas muy jóvenes. Disponen de tiendas especiales con diseño de vanguardia, lugares informales de encuentro donde las potenciales clientas suelen disponer de música, arte, videos, revistas y graffitti. Stradivarius, va destinado a un público joven que desea una rápida traducción de las ideas de la pasarela en términos de un atuendo callejero.?

El ajustado conocimiento de las preferencias de los consumidores se obtiene por una triple vía: en primer lugar, a partir de la información que proporcionan las pasarelas internacionales y los grandes modistos; en segundo lugar, a través de los equipos de informadores que recorren los ambientes frecuentados por los consumidores potenciales (discotecas, universidades, sitios de ocio); en tercer lugar, y muy importante, por medio de información que transmiten los vendedores

\footnotetext{
${ }^{7}$ Es una estrategia utilizada por Zara y por Benetton a través de sus franquicias.
} 
de las tiendas o los puntos de venta. Toda esta información se procesa y se envía a los departamentos de diseño y de allí a la producción. Esto permite conocer en tiempo real, y con unos costes bajos, los artículos, las tallas, los diseños, los colores más solicitados y adaptar el producto a la demanda real (Alonso Alvarez, 2000). El crecimiento del consumo y la fragmentación del gusto ha alterado sutilmente el modo en que se produce, distribuye, comercializa y vende la moda ${ }^{8}$. Esto ha servido para crear significados en torno a los artículos hasta el punto de que lo que se consume es la imagen, no el objeto en sí. El expandido mercado de imágenes sobre la industria de la moda ha creado la necesidad de una nueva fuerza laboral de creadores de imágenes y, una vez más, los intermediarios culturales entran en escena para desempeñar su función.

Conocidas sus preferencias y satisfechas eficazmente en términos de producto, se trata de buscar la fidelización de los clientes. La norteamericana Gap, la sueca $H \& M$ lo hacen, por ejemplo, a través de la propaganda directa en los médios de comunicación,y gasta anualmente entre un $4 \%$ y un $5 \%$ de sus ingresos en publicidad. El promedio de las firmas del sector se sitúa en un 3,5\%. Inditex, por el contrario, sólo destina a ello un $0,3 \%$ porque considera este tipo de mercadotecnia muy poco eficiente en tanto que el resultado obtenido no compensa las inversiones realizadas. Por ello esta empresa nunca se anuncia a sí misma, salvo las dos veces prescriptivas que imponen las rebajas estacionales, y aun entonces, lo realiza de una manera elemental y discreta. Inditex se sitúa, así, en las antípodas de Benetton y sus campañas de publicidad salvajes. La tienda es para Inditex, un factor básico, a estos efectos, por lo que debe estar en la principal ciudad, en la mejor zona, en la calle más comercial y en la esquina más atractiva.

En la sociedad de la información el hecho de no emplear publicidad directa no implica la renuncia a la promoción de sus marcas. En primer lugar, un recurso tan elemental como el boca a boca para transmitir, por ejemplo, un slogan tan poco original como el de la adquisición de un producto de diseño a precios asequibles que utilizan todos los killers es un elemento muy valioso en el marketing del grupo. En segundo lugar, funciona también como poderoso reclamo, tal como se ha señalado ya en el caso de Inditex, el diseño exterior de sus puntos de venta, situados todos ellos en áreas muy concurridas y con escaparates que difícilmente pasan desapercibidos. A todo ello une unos interiores muy estudiados, adaptados al público que los visita, y que son el resultado del trabajo minucioso de un equipo de arquitectos e interioristas que relaciona los metros cuadrados de superficie con la disposición del producto, el volumen de la música ambiental y las luces directas e indirectas.

${ }^{8}$ MSDW (2000). Estos precios se calculan según el procedimiento del target pricing, algo relativamente frecuente en el sector de la confección. 
RIS

REVISTA INTERNACIONAL DE SOCTOLOGIA

No 39, SEPTIEMBRE-DICIEMBRE, 2004

ANA MARTINEZZ BARREIRO

Desde hace algunos años la cultura de empresa se ha preocupado también por instaurar el referente ético en la empresa como una estrategia más de marketing, con el fin de reforzar y ganar sectores de mercado mediante nuevas políticas de comunicación y de productos marcas y mejorar la imagen corporativa de las empresas. Concretamente, se ha instaurado un nuevo tipo de marketing que afirma explícitamente su preocupación por los valores éticos y posiciona las marcas y los productos sobre una base moral. Ha llegado la hora del "marketing de la solidaridad", de la empresa ciudadana (Lipovetsky, 2003: 68). En este sentido, por ejemplo, el grupo Benetton se ha interesado en construir su imagen de marca basándose en el antirracismo y el llamamiento a la tolerancia. Se trata de crear por esa vía una buena imagen corporativa ante los consumidores, algo que se está convirtiendo en un nuevo factor de competitividad'.

Por lo que respecta a la expansión en el mercado internacional, está impregnada también de esa estrategia flexible de la que hablaba más atrás. La mayoría de las firmas del sector se expansionan de manera selectiva a través de franquicias, joint-ventures o filiales, independientemente de los países a donde acuden. Inditex ha logrado adaptarse a las peculiaridades de cada mercado de destino. De ese modo, en áreas muy competitivas, de bajo riesgo o con grandes posibilidades de crecimiento - lo que cubre gran parte de Europa occidental y toda la América anglosajona y latina - adopta una posición de crecimiento a través de filiales. En mercados poco conocidos pero muy competitivos, lo hace a través de joint ventures que suavizan el efecto aprendizaje - es el caso de Japón y de Alemania. Y en situaciones de alto riesgo, ventas bajas, o ambas, en donde el coste de crear tiendas propias es muy elevado, actúa a través de franquicias (Oriente próximo y países escandinavos). El resultado es que Inditex puede ofrecer unos precios exteriores un $15 \%$ de promedio más bajos que sus rivales directos ${ }^{10}$, que le permiten una política agresiva, pero flexible y muy segura de expansión (una media de 70 nuevas tiendas en el extranjero en los tres ejercicios últimos) en un momento de caída internacional de la demanda que ha hecho retroceder a gran parte de sus competidores como la norteamericana Gap.

\footnotetext{
${ }^{9}$ Respecto a la teorización sobre las subculturas juveniles Cfr: Dick Hebdige (1979), Frith, Simon (1996) afirma que el origen de los punk, se encuentra en el nexo entre las escuelas de artes y la música rock. por su parte, J. Clarke (1992) investiga a los skinhead. P. Wills $(1975,1978)$ estudia el "acople" entre los intereses principales de la subcultura juvenil y su indumentaria a través del concepto de la homología. Veasé, también Barker, M. y A. Beezer (1994), Introducción a los estudios Culturales, Barcelona, Bosch.

${ }^{10}$ Para Entwitle (2002:170) esto es una forma de capital subcultural.
} 


\section{MODA Y CULTURA: LA ESTÉTICA COMO EXPRESIÓN DEL AMBIENTE TRIBAL}

\section{Moda y Cultura}

Tal como resulta de lo anterior, la moda es el resultado de una serie de prácticas interconectadas: prácticas de mercado y económicas, desarrollos tecnológicos y una serie de prácticas más culturales como el marketing y el diseño. Hasta hace nada, los conceptos de "negocio" y "cultura" eran incompatibles. No obstante, a partir de los años ochenta la conexión negocio y cultura es un medio esencial para asegurar el éxito empresarial. En la actualidad se emplea el término economía cultural para describir el modo en que la cultura y la economía se relacionan de una forma tan compleja que ninguna esfera determina a la otra. La cultura y la economía son híbridos que se constituyen mutuamente el uno al otro. Ninguna actividad es puramente económica; todas las decisiones económicas implican otras de carácter más cultural. La cultura está a su vez afectada por manifestaciones y decisiones económicas. El significado cultural es creado con frecuencia en lugares económicos, en el trabajo y en las tiendas. Desde esta perspectiva podemos observar una serie de prácticas que vienen a aclarar más la relación entre economía y cultura cuando éstas se unen en la experiencia de los lugares de venta como las tiendas y los centros comerciales. Estos espacios anulan la diferencia entre lo cultural y lo económico, ya que comprar es tanto una actividad económica como cultural. La expresión "ir a ver escaparates" sugiere que los artículos consumidos no son materiales sino que la tienda es auténtico espectáculo.

Algunos estudios sobre los usos de los espacios de consumo (como Shields, 1992; Sigter, 1993, 1997; y Du Gay, 1997) afirman que en la organización espacial de estos lugares está implicada la propia constitución de las identidades posmodernas, ya que estos lugares no son sólo espacios para el consumo de artículos e imágenes, sino que desempeñan un papel esencial en la expresión de la identidad y de la subjetividad de la cultura postmoderna. Tal como demuestra Foucault (1997), el espacio nunca es inerte sino que está activo en la constitución de las relaciones sociales. La organización espacial de las calles y los edificios produce un impacto en los movimientos de los cuerpos y organiza el flujo de las masas hacia ciertos tipos de actividades y relaciones. Estas investigaciones también han hecho hincapié en el hecho de que el diseño de las tiendas "atrae las miradas" e "incrementa el consumo". Al parecer, el diseño, la luz, el mobiliario y los materiales que se emplean desempeñan un papel esencial en conjugar la producción con el consumo al asociar los bienes y los servicios con significados culturales particulares y enfocados a los posibles compradores" (Du Gay, 1997:5). 
RIS

REVISTA INTERNaCIONAL DE SOCIOLOGIA

No 39, SEPTIEMBRE-DICIEMBRE, 2004

ANA MARTÍNEZ BARREIRO

\section{Moda e Individualismo}

La globalización está cambiando el carácter de nuestra experiencia cotidiana. A medida que las sociedades en que vivimos sufren profundas transformaciones, las consolidadas instituciones que solían sostenerlas van quedando fuera de lugar. Esto esta obligando a una redefinición de aspectos íntimos y personales de nuestras vidas como la familia, los roles de género, la sexualidad, la identidad personal, nuestras interacciones con los demás y nuestra relación con el trabajo. La idea que tenemos de nosotros mismos y de nuestras conexiones con el resto de las personas se está alterando profundamente a través de la globalización. En las sociedades actuales los individuos tienen más oportunidades que antes para configurar su propia vida. Hubo un tiempo en el que la tradición y la costumbre ejercían una acusada influencia en la vida de las personas. Factores como la clase social, el género, el origen étnico e incluso el credo religioso podrían cerrarles ciertas vías a los individuos y abrirles otras. En épocas pasadas, la identidad personal de los individuos se formaba en el contexto de la comunidad en la que nacían. Los valores, formas de vida y ética predominantes en ella proporcionaban directrices relativamente fijas que las personas seguían en su existencia.

En las condiciones de la globalización, nos enfrentamos a una tendencia que se orienta hacia un nuevo individualismo en que los seres humanos han de constituirse activamente y desarrollar su propia identidad. El peso de la tradición y de los valores establecidos se retira a medida que las comunidades locales van interactuando con un nuevo orden global. Los "códigos sociales" que antes guiaban las opciones y actividades de las personas se han relajado considerablemente. Los marcos de la identidad tradicional se están disolviendo y emergen nuevas pautas en este sentido. La globalización nos está obligando a vivir de una forma más abierta y reflexiva. Esto significa que estamos constantemente respondiendo al entorno cambiante que nos rodea y ajustándonos a él. Incluso las pequeñas opciones que tomamos en nuestra vida cotidiana (lo que nos ponemos, cómo empleamos el tiempo libre, de qué manera cuidamos la salud y el cuerpo) forman parte de un proceso continuado de creación y recreación de nuestra propia identidad.

Como consecuencia del individualismo contemporáneo ha emergido una nueva línea de investigación que es definida como la perspectiva multicultural de la moda y que está representada fundamentalmente por Lipovetsky, Morace, Maffesoli y Stuar Hall. En efecto, tras la crisis de las utopías revolucionarias y la caída de los colectivismos asistimos hoy a una revilitación del individualismo que conlleva, entre otros efectos importantes, un desplazamiento del interés publico a lo privado y un ensalzamiento de los valores asociados a éste último. Esta mudanza, que es definida como la "segunda revolución individualista" (Lipovetsky, 1986:9), se traduce en el declive de la moral centrada en el deber y la transformación privada 
del individuo ${ }^{11}$. En este sentido, los valores permisivos hedonistas y psicologistas relevan a los valores disciplinarios y rigoristas, que eran dominantes en la cultura del industrialismo burgués hasta el desarrollo de la sociedad de consumo y la comunicación de masas. En efecto, el individualismo narcisista se convierte en el nuevo trasfondo moral de las sociedades contemporáneas. En el ámbito de la moda, uno de los cambios que testimonian la emergencia de personalidades narcisistas, propias del individualismo contemporáneo, es que, paralelamente a la apariencia legítima, aparecen nuevos comportamientos individuales y colectivos en ruptura con el momento anterior: se pone fin al régimen disciplinario de la apariencia y surge la aparición de la multiplicidad estética de la moda.

\section{Moda y Tribalismo}

Frente al individualismo de Lipovetsky y el narcisismo de Lasch surge "otra corriente del pensamiento que cuestiona el papel exclusivo del yo y realza la importancia de la extensibilidad del yo en tribus a las que se pertenece simultáneamente o sucesivamente. Ésta es las hipótesis que Maffesolí (1990) expone en su libro Los tiempos de las tribus, al asegurar que nuestro principio de siglo exhibe una sociabilidad caracterizada por una dialéctica constante entre la masificación creciente y el desarrollo de unos micro-grupos llamados tribus. En este sentido, para poder reflexionar sobre el devenir de la moda, hay que aclarar la idea de por qué hoy asistimos al reemplazamiento de una identidad estable por un portador de máscaras sucesivas en esferas sociales cambiantes. En relación con la persona, hay que llamar la atención de que tenemos una multiplicidad de yoes, en cuanto que en cada momento soy otro. Por consiguiente, lo que caracteriza y lo que marca nuestro tiempo es la estética como expresión efectiva del ambiente tribal. Esta idea de tribu hace que estemos entrando en un tipo de sociedad en el que va a dominar la idea de extensibilidad del yo, un ego que se pierde en la tribu. Cuando uno se viste de la misma manera que se viste su tribu ya no tiene, propiamente hablando, un solo ego: hay aquí un ego extensible. Cuando uno lleva el uniforme punk, o uno lleva el traje burgués de tres piezas, se pierde en su tribu; y si en otro momento del día lleva otro uniforme (cambia, por ejemplo, su traje tres piezas por el blue jean, o por cualquier otro vestido de sport) entra en otra tribu. De ahí, que haya algo de extensible en mi identidad, pues no soy únicamente estable, me pierdo mediante la idea de extensibilidad del yo.

\footnotetext{
${ }^{11}$ Los países asiáticos han sido objeto de una occidentalización de su moda. Invadidos de firmas multinacionales producidas en Shangai. Se trata de una coyuntura de causas excepcionales, como la llaman Waquet y Laporte (1999:104) refiriéndose a la explosión del comercio internacional de la moda en el mercado Asiático.
} 
RIS

REVISTA INTERnacional DE Sociologia

№ 39, SEPTIEMBRE-DICIEMBRE, 2004

Durante mucho tiempo uno de los conceptos básicos que había caracterizado a la sociedad moderna era el concepto de separación, tal como ha sido formulado por la tradición sociológica francesa, Maffesolí (1990) piensa que este concepto de separación, de distinción, está superado y lo que se aplica a la modernidad es la integración emocional, a través del paradigma estético. En este paradigma estético, la mezcolanza vestimentaria, los cabellos multicolores, la manera de reutilizar los vestidos retros, tienen la función de cemento, de unirme a los otros. En este sentido, la apariencia, el retorno de la imagen a un primer plano, va a tener una función de tipo comunitario. Pero se trata de un sentimiento y de una experiencia compartida que hacen que sea siempre en el interior de un grupo donde yo experimente algo y donde tenga que expresarme. Esto le lleva a decir a Maffesolí que no hay narcisismo en las sociedades postmodernas, sino más bien una especie de sujeto colectivo, una extensibilidad del yo, la cual aparece particularmente representada en especies de reagrupamientos de tipo puntual. Las grandes ciudades modernas nos ofrecen buenos ejemplos de estas agrupaciones cuando uno observa en la vida cotidiana la representación en público de la sucesión de clichés: jogging, punk, el look retro o la moda grunch, etc. Todo esto da buena cuenta de este proceso tribal, que es el proceso de la modernidad. De ahí, la importancia de la apariencia que, de modo internacional, se llama look.

Según Davis (1992), Finkelstein (1991) y Giddens(1991), vivimos en un mundo en el que las identidades ya no son estables y donde el anonimato de las grandes ciudades nos permiten experimentar con nuestra imagen. El yo moderno cada vez es más consciente de sí mismo, lo que incluye la propia imagen, y es capaz de intervenir y actuar sobre ella. Las subculturas juveniles utilizan el estilo, la ropa, el cuerpo, la postura, etc, para crear su identidad de forma consciente, tanto para afirmar su afiliación al grupo como para diferenciarse de los que están fuera y dentro del mismo. La vestimenta nos abre nuevas posibilidades para enmarcar el yo, aunque sean temporales. El seguir las modas "abre, a la vez que recorta, la posibilidad del desarrollo individual del yo y de la cooperación social" (Wilson, 1985: 63). No obstante, la moda no produce soluciones simbólicas permanentes: sus símbolos son demasiado efímeros y su ambivalencia está demasiado afianzada. En el mundo moderno, la indumentaria viene a desempeñar un papel importante en el modo en que hacemos frente a dicha ambivalencia. Por consiguiente, cuando hablamos de la individualidad y de la identidad y del papel desempeñado por la moda y el vestir, es importante reconocer que las identidades tienen un sentido social. El individuo puede querer "destacar", pero también quiere "encajar" dentro de un grupo.

Para investigar el vestir en la cultura contemporánea hemos de examinar el estilo subcultural e indagar de qué forma este estilo expresa una preocupación por la imitación y la diferenciación. Simmel (1988) sostiene que la distinción es un rasgo característico de la moda. No obstante, en la cultura contemporánea ésta no se transmite por los linajes de clase, sino a través de un amplio plano de 
identidades sociales. Por una parte, las sub-culturas juveniles utilizan la ropa para señalar identidades distintas, entre ellos y entre la cultural principal (Clarke 1992: 55). Comparten algo de su "cultura matriz" pero tratan de expresar sus propias preocupaciones e intereses a través de un estilo distintivo y unos patrones de vida diferentes como se da entre las distintas tribus urbanas como los rockers, skinheads, punk y otras.

Tal como ha señalado el mismo Simmel (1988), la moda se basa en la tendencia contradictoria hacia la similitud. Esta característica también es visible en las subculturas juveniles, que se acogen al estilo para manifestar la clara identidad de los miembros que se encuentran dentro de ella, frente a los que están fuera. En este sentido, el estilo expresa el grado de compromiso con el grupo e indica a los que están fuera la oposición a los valores del momento. El estilo es la combinación del modo en que se lleva la prenda, se combina con otras, así como la forma de llevarlas, y no sólo expresa la identidad de clase, sino identidades subculturáles (Barke, 1994). A este respecto, el estilo es el "tejido conectivo" que resulta de nuestro sentido de interconexión con grupos concretos, haciendo visible nuestro compromiso con una comunidad en particular (Wilson, 1985), y Y, produce sus prácticas corporales y sus propias formas de hablar ${ }^{12}$. Asimismo, McRobbie (1994) argumenta que existen varias interpretaciones del estilo hippie. Este estilo, por una parte, representa un rechazo al estilo de vida consumista de los años sesenta por considerarla un derroche y ecológicamente perjudicial; $y$, por otra, indica una identificación con los pobres, así como un rechazo del estilo de la clase media alta. De cualquier manera, la mayoría de las sub-culturas juveniles han confiado en la ropa usada o pasada de moda para crear su propio estilo.

\section{Globalización frente a Homogeneización, Fragmentación y Convergencia Cultural}

$\mathrm{Al}$ analizar el flujo de la cultura posmoderna y el consumo global se observa que el intercambio de estos signos crea la posibilidad de "compartir identidades", por ser consumidores de las mismas mercancías, clientes de los mismos servicios, oyentes de los mismos mensajes y videntes de las mismas imágenes, entre personas que están alejadas en el tiempo y en el espacio (Hall, 1997: 621). En la actualidad, uno de los signos más emblemáticos son los jeans o las zapatillas que parecen ser un uniforme universal de la juventud occidental y de la cultura joven oriental, no sólo a causa del mercado global de consumo de imágenes, sino porque actualmente los jeans y las zapatillas se producen en Taiwán para los mercados de Nueva York. La vida social se ha vuelto mediatizada por un mercado global de estilos, de lugares y de imágenes; gracias a los viajes y a los desplazamientos nos estamos confrontando simultáneamente con diferentes identidades, en un gigantesco supermercado cultural. Este fenómeno social se conoce con el término de "homogeneización cultural"; en ese marco los accesorios 
RIS

REVISTA INTERNACIONAL DE SOCIOLOGIA

№ 39, SEPTIEMBRE-DICIEMBRE, 2004

ANA MARTÍNEZ BARREIRO

como los bolsos, pañuelos, cinturones, etc. se vuelven claves, porque permiten a sus portadores circular simultáneamente en diferentes lógicas de representación, teniendo como valor agregado el hecho de volverse en sí mismo portador de un valor de diferenciación/ homogeneización cultural (Escudero, 2001: 103-119). No obstante, frente a la tendencia hacia la homogeneización global hay también una fascinación por lo local que provoca simultáneamente nuevas identificaciones tanto locales como globales.

Hoy en día vivimos en un único orden global informativo: en una enorme red global en que la información se comparte rápidamente y en grandes cantidades. Un simple ejemplo puede ilustrar este punto con claridad. ¿Qué nos dice el éxito de la película Titanic sobre la globalización?. Por una parte, el éxito de la película dice que la globalización es una forma de "imperialismo cultural" mediante la cual los valores, estilos y perspectivas del mundo occidental se extienden de forma tan agresiva que asfixian a todas las culturas nacionales. Por el contrario, hay otros que vinculan el proceso de globalización con una creciente diferenciación de las tradiciones y manifestaciones culturales. Para estos últimos, la sociedad global no se caracteriza por la homogeneidad cultural, sino por la enorme diversidad de culturas que proceden del exterior, y que ofrece a las personas para que elijan una gama de opciones en cuanto a estilos de vida. No estamos presenciando una cultura global unificada sino una fragmentación de las formas culturales (Baudrillard, 1988). Las identidades establecidas y las formas de vida arraigadas en las comunidades locales y culturales están dando paso a nuevos tipos de "identidades híbridas", compuestas de elementos procedentes de fuentes culturales contradictorias (Hall, 1992). De este modo, hoy en día, una persona de un ámbito urbano de Sudáfrica puede continuar estando muy influida por las tradiciones y perspectivas culturales de sus raíces tribales, al mismo tiempo que adopta estilos y gustos cosmopolitas en su vestimenta, en sus actividades de tiempo libre y todo conformado por fuerzas globalizadoras.

En efecto, el desarrollo del mercado mundial, tiene consecuencias importantísimas para las culturas, identidades y modos de vida. La globalización del quehacer económico está acompañada de olas de transformación cultural, en el seno de un proceso denominado como "globalización cultural". Se trata principalmente de la fabricación de símbolos culturales y de una realidad que se viene observando desde hace ya bastante tiempo. Una buena parte de la sociología ha adoptado para este problema una postura que se acerca bastante a la tesis de la "convergencia de la cultura global". Según dicha tesis, se está produciendo una paulatina universalización, en el sentido de unificación de modos de vida, símbolos culturales y modos de conducta transnacionales. Tanto en Singapur, Madrid o México, se llevan los mismos vaqueros. En una palabra: que la industria de la cultura global significa cada vez más la "convergencia" de símbolos culturales y de formas de vidas. Bajo el discurso del mercado mundial subyace, según esta perspectiva, una utopía negativa, y es que está surgiendo un solo mundo, pero no como recono- 
cimiento de la multiplicidad, pluralista y cosmopolita de uno mismo y del otro, sino más bien todo lo contrario, como un solo mundo mercantil. Las culturas y las identidades se desarraigan y se sustituyen por símbolos mercantiles, procedentes del diseño publicitario y de los iconos de las empresas multinacionales. La esencia se convierte en diseño y esto vale para todo el mundo. Las empresas que se proponen dominar el mercado con la fabricación de símbolos culturales universales utilizan a su manera el mundo sin fronteras de las tecnologías de la información, y donde los satélites de la comunicación permiten superar todas las barreras de clase y las fronteras nacionales. Esta última consideración nos confirma que las nuevas modas se propagan como el sida y las epidemias.

\section{CONCLUSIÓN}

En síntesis, y como conclusión, cabe decir que la globalización económica y cultural hace un mundo global tanto como una moda global, donde la circulación planetaria de las modas se produce gracias al cambio del industrialismo al informacionismo. Este cambio trajo consigo toda una serie de avances recientes dentro del sistema de la producción textil que tienen que ver con la oferta y la demanda y han supuesto unas indiscutibles ventajas competitivas para el sistema de la moda en la actualidad. Una de las primeras características del sistema de producción de la moda contemporánea es la aparición de la producción flexible apoyada por el despliegue de las nuevas tecnologías informáticas y el modelo just in time. Otra de las claves se encuentra en los soportes mediáticos donde los productos culturales o las modas circulan de forma global. Todos estos cambios nos llevan a certificar la globalidad de la moda, y nos conduce a reconsiderar que la difusión cultural de la moda se mueve desde distintos puntos de partida y en varias direcciones, en lugar de emanar de una sola fuente, o "filtrar hacia abajo".

\section{BIBLIOGRAFÍA}

ALONSO ÁlVAREZ, L (2000), "Inditex-Zara. Vistiendo a tres Continentes", en F. Ojea (coord.), Grandes empresa, grandes historias de Galicia, A Coruña, Voz de Galicia.

(2000), "Vistiendo a tres continentes: la ventaja competitiva del grupo Inditex-Zara, 1963-1999", Revista de Historia industrial, $\mathrm{n}^{\circ} 18, \mathrm{pp}: 157-179$.

BARKER, M. y A. BEEZER (1994), Introducción a los estudios Culturales, Barcelona, Bosch.

BAUDRILLARD, J. (1974), La sociedad de consumo: sus mitos, sus estructuras, Barcelona, Plaza \& Jané, pp.92-100.

BLACKMORE, S. (2000), La maquina de los memes, Barcelona, Paidós. 


\section{RIS}

REVISTA INTERnacional DE SOClocogta

BLANCO, F. y POLO REDONDO (2000), “Inditex (1994-1999), en JL. Munuera Alemán y A.I Rodríguez Escudero, Estrategias de marketing para un crecimiento rentable, Madrid, Esic Editores.

BLUMER, H.(1968), “Moda”, Enciclopedia Internacional de las Ciencias Sociales, Madrid, Aguilar, pp. $155-157$.

BOURDIEU, P. (1991), La Distinción, Madrid, Taurus.

BRAHAM. P. (1997), “Fashion: Unpacking a Culture Production”, en P. Du Gay (comp), Production of Culture, Cultures of Production, Londres, Sage.

BONACHE PÉREZ, J. y J. CERVIÑO FERNANDEZ (1996), "Caso Zara: el tejido internacional", en Juan José Durán Herrera (coor), Multinacionales Españolas. I. Algunos casos relevantes, Madrid, Pirámide, pp. 51-58.

CAMPBELL, C. (1989), The Romantic Ethic and the Spirit of Modern Consumerism, Oxford, Basil Blackwell.

(1993), "Understanding Traditional and Modern Patterns of Consumption in Eighteenth-Century England : A Character-Action Appoach", en J.Brewer y R.Porter (comps), Consumption and the World of Good. Nueva Yok, Routledge.

(1997), "When the Meaning is not a Message: A critique of the Consumption as Comunication Thesis", en M. Nava, A. Blake, I. MacRury y B. Richards (comps), Buy this Book: Studies in Advertising and Consumption, Londres, Routledge.

CASTELLS, M. (1997), "La empresa en red: cultura, instituciones y organizaciones de la economía informacional", en La era de la información: Economia, sociedad y cultura. Vol. 1, Madrid, Alianza, pp:179-223.

(1998) "Paraisos comunales: identidad y sentido en la sociedad red" en La era de la información: Economia, sociedad y cultura. Vol.2, El poder de la identidad. Madrid, Alianza, pp. 27-90.

CASTELLANO, J.M. (1993), "Una ventaja competitiva: el factor tiempo. El caso Inditex-Zara», Papeles de Economía Española, 56:402-404.

CABANELAS OMIL, J. (1997), Dirección de empresas en un entorno abierto y dinámico, Madrid, Pirámide.

CLARKE, J.S., T. HALL, JEFFERSON y B. ROBERTS (1992), "Subcultures, Cultures and Class", en T. Bennett, G Martin, C. Mercer y Wollacott (comps.), Culture, Ideology and Social Process: A Reader, Milton Keynes, Open University Press.

CORIAT, B. (1993), El taller y el robot: ensayos sobre el fordismo y la producción en masa en la era electronica, Madrid, Siglo Veintiuno.

(1994), "Neither pre-nor post-fordism:an original and new of managing the labour process", en K. Tetsuro y R. Steven (eds.), Is Japanese Management Post-Fordism?, Tokio, Mado-sha, pp. 182.

CRAIK, J. (1993), The Face of Fashion. Culture Studies on Fashion. Londres, Routledge. 
DAWKINS, R. (2000), El gen egoista: las bases biologicas de nuestra conducta, Barcelona, Salvat Ciencia.

DAVIS, F. (1992), Fashion, Culture and Identity, Chicago, University of Chicago,Press, Chicago.

DU GAY, P. (1997), Production of Culture, Cultures of Production, Londres, Sage.

ENTWISTLE, J. (2002,) El Cuerpo y la Moda, Barcelona, Paidos.

ESCUCERO, L. (2001), “Lógicas en la representación de la moda”, deSignis, n 1, pp: 103-119.

FINE, B. y E. LEOPOLD (1993), The World of Consumption, Routledge, Londres.

FINKELSTEIN, J. (1991), The Fashinned Self, Cambridge, Polity Pres.

FRITH, S. (1996), "Music and Identity", en Questions of Cultural Identity, Londres, Sage.

GIDDENS, A (1997), Modernidade Identidad del Yo: el Yo y la sociedad en la época contemporánea, Barcelona, Península.

GOLDMAN SACHS INVESTMENT RESEARCH (2000), Apparel Retailing: The Next Global Sector, Londres y Nueva York, Goldman, Sachs and Co.

HALL, S. (1997), "The Question of Cultural Identities", Modernity: An introduction to Modern Society en S. Hall, D.Held et al, Oxford, Blackwel.

HEBDIGE, D. (1979), Subculture. The meaning of Style, Londres, Methuen.

IGLESIAS PÉREZ, M. (2000), "El cooperativismo textil gallego", en La industria de la moda en Galicia, Santiago, Idega.

INDITEX (1984-1999), Informes anuales.

KATZ, E. y P. LAZARSFELD (1970), La influencia personal. El individuo en el proceso de comunicación de masas, Barcelona, Hispano-europea .

KING. C.W. (1981), "Fashion adoption: a rebuttal to the Trickle Down Theory", B.G., Sproles, (ed), Perspectives of Fashion, Minneapolis, Burgess.

KONIG, R. (1972), Sociología de la moda, Barcelona, A. Redondo editor.

LEOPOLD, E (1992), "The Manufacture of the Fashion System", en J. Ash y E Wilson (comps), Londres, Chic Thrills.

LIPOVETSKY, G (1990), El imperio de lo efimero. La moda y su destino en las sociedades modernas, Barcelona, Anagrama.

(1986), La era del vacio, Anagrama, Barcelona.

(2003), Metamorfosis de la cultura liberal, Anagrama, Barcelona. 
RIS

REVISTA INTERNaCIONAL DE SOCIOLOGIA

MAFFESOLI, M. (1990), Los tiempos de las Tribus. El declive del individualismo de la sociedad de masas, Barcelona, Icaria

MARTINEZ BARREIRO, A. (1998), Mirar y Hacerse Mirar. La moda en las sociedades Modernas, Tecnos, Madrid.

(1998), “La moda en las sociedades avanzadas”, Papers, n54, pp.129-137.

(2000), “Cómo Configuran los Españoles su Vestuario?, RIS, n²5, pp. 77-98.

McCRAKEN,G.D. (1985), The Tricklen-Down Theory Rehabilitaded, Nueva York, Lexington Book.

McROBBIE (1994), Post-Modernism and Popular Culture, Londres, Routledge.

MORGAN STANLEY DEAN WITTER (1999), Retailers-General, Speciality Clothing, Londres y Nueva York, MSDW.

(2000), Speciality Clothing Report.21 $1^{\text {st }}$ Century Strategy, Londres y Nueva York, MSDW.

PARTINGTON, A. (1992), "Popular Fashion and the Working- Class Affluence", en J. Ash y E. Wilson (comps), Chic Thrills: A Fashion Reader, Londres, Pandora.

PIORE, M.J. y F. CHARLES F Sabel (1990), La segunda ruptura industrial, Madrid, Alianza Universidad.

POLHEMUS, T. (1994), Streetstyle, Luton, Lennard.

RAGONE, G. (1986), Sociología dei fenomeni di moda, Milán, Franco Angeli.

ROUSE, E (1989), Understanding Fashion, Londres, BSP Professional Books.

SHIELDS, R. (1992) (comp.), Lifestyle Shopping: The Subject of Consumtion, Londres, Routledge.

SIMMEL. G (1988), Sobre la aventura: ensayos filosóficos, Barcelona, ed. Península.

SINGLETON, J. (2000), The World Textile Industry, Londres y Nueva York, Routledge, $2^{\mathrm{a}}$ edición.

SLATER, D.R (1993), "Going Shopping:Markets, Crowds and Consumption" en Jenks (comp), Cultural Reproduction, Londres, Routledge.

(1997), Cultural and Modernity, Cambridge, Polity Press.

SQUICCIARINO, N (1990), El vestido Habla. Consideraciones Psico-sociológicas sobre la vestimenta, Cátedra, Madrid

SPENCER, H. (1974), Principios de sociología, Buenos Aires, ed: Revista de Occidente.

TARDE, G. (1991), Les Lois Dîmitation. París, Ed. Alcan.

164 
VALDIVIESO, J.Mª y S. LÓPEZ (2000), Historia económica de la empresa, Barcelona, Crítica.

VÁZQUEZ GARCÍA, S. (2000), «El modelo Zara», en R. C. Lois González, A.I. Fernández González, et al., La industria de la moda en Galicia, Santiago, Idega

VEBLEN, T. (1974), Teoría de la Clase ociosa. México, ed: Fondo de Cultura Económica.

VERDU, V. (2004), El estilo del mundo. La vida en el capitalismo de ficción, Anagrama, Barcelona.

WISWEDE, G. (1971), "Theorien der Mode aus soziologischer Sicht", Jahrbuch der_Absatz und Verñbrauchsforschung, 1.

WILSON, E (1985), Adorned in Dreams: Fashion an Modernity, Londres, Virago. 